\title{
Acute Toxicity Tests of Fermented Robusta Green Coffee Using Zebrafish Embryos (Danio rerio)
}

\author{
Tedjo Narko ${ }^{1,2}$, Marlia Singgih Wibowo ${ }^{1, *}$, Sophi Damayanti ${ }^{1}$, Indra Wibowo ${ }^{1}$
}

Tedjo Narko ${ }^{1,2}$, Marlia Singgih Wibowo ${ }^{1, *}$, Sophi Damayanti ${ }^{1}$, Indra Wibowo ${ }^{1}$

'Bandung Institute of Technology, Jalan Ganesha 10 Bandung, INDONESIA.

${ }^{2}$ Poltekkes TNI AU, Jalan Ciumbuleuit No.203 Bandung, INDONESIA.

\section{Correspondence}

\section{Marlia Singgih Wibowo}

Bandung Institute of Technology, Jalan Ganesha 10 Bandung

email: marlia@fa.itb.ac.id

History

- Submission Date: 20-1-2020;

- Review completed: 07-02-2020;

- Accepted Date: 26-02-2020

DOI : 10.5530/pj.2020.12.75

Article Available online http://www.phcogj.com/v12/i3

\section{Copyright}

(C) 2020 Phcogj.Com. This is an openaccess article distributed under the term of the Creative Commons Attribution 4.0 International license.

\begin{abstract}
Background: Green coffee beans are coffee beans of coffee fruit that have not yet been roasted. The use of green coffee beans as a weight-loss agent has been widely used worldwide, but nowadays there is a new way to enjoy coffee by adding kombucha culture to it, or what is known as kombucha coffee. The development of this fermented product preparation still requires a more in-depth study, one of which is related to the toxicity of the kombucha green coffee preparation. Objective: This research was aimed to determine LC $_{50}$ values for robusta green coffee fermented with kombucha culture using zebrafish (Danio rerio) embryos using an in vivo method. Methods: This study observed the development of 20 zebrafish embryos administered one of five different concentrations of kombucha coffee preparation 24 hours up to 96 hours, with the experiment repeated three times. The percentage of embryo deaths was observed and analyzed using a probit model for $\mathrm{LC}_{50}$ concentration and analyzed using

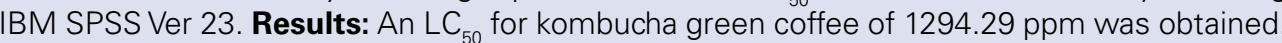
Statistical tests on the concentration of kombucha coffee extracts were not significant differences with $\mathrm{p}$-values $>0.05$. Conclusion: The $\mathrm{LC}_{50}$ of robusta green coffee extract using zebrafish embryos of 1294.29 ppm included in the safe category.
\end{abstract}

Key words: Green coffee, Kombucha, Toxicity, Zebrafish embryos.

\section{INTRODUCTION}

Coffee plants are included in the genus Coffea, family Rubiaceae. The genus Coffea has more than 100 species. Of these, there are three species that are cultivated for commercial purposes, namely Coffea arabica, Coffea canephora, and Coffea liberica. In general, only the seeds of coffee plants are used and extracted from as drinks. But in some societies, there are also those who consume the leaves by brewing such as tea leaves.

Indonesia has great opportunities and excellent prospects for developing coffee in terms of both domestic consumption and export markets. The demand for coffee worldwide is quite large and shows an increasing trend. Data from the International Coffee Organization shows that the recent increasing trend in world coffee consumption began in 2010 with an average increase of $2.5 \%$ / year. In 2020, it is estimated that world coffee needs will reach 10.3 million tons. ${ }^{1}$ Coffee is an agricultural commodity in Indonesia that has further economic value, as it contains a variety of chemical compounds with different characteristics and requires research in its biological activities development. ${ }^{2}$ Most of the coffee beans traded globally are produced from the Coffea arabica and Coffea canephora, which has the popular names arabica and robusta coffee, respectively. The remaining insignificant amount is made from Coffea liberica, which is traded under the name of liberica or excelsa coffee. ${ }^{3}$

Green coffee beans are coffee beans that have not yet been roasted. Green coffee contains various chemical compounds such as carbohydrates, proteins, minerals, caffeine, trigonelline, aliphatic acids (carboxylic acids), chlorogenic acids, fats, and derivatives, glycosides, and volatile components. Chlorogenic acid is one of the isolated compounds with antioxidant activity found in a large number of coffee varieties. ${ }^{4,5}$ Chlorogenic acid belongs to the hydroxycinnamic acid group, ${ }^{6}$ a member of the larger polyphenol group, many members of which have antioxidant activity. The polyphenol content found in robusta coffee is higher than arabica coffee or other plants. ${ }^{7}$ Chlorogenic acid in green coffee is considered to have health benefits for heart disease, diabetes, weight loss, and others. Several clinical trials on humans have been conducted to test the effectiveness and safety of chlorogenic acid in green coffee to reduce body weight and body mass in adults. ${ }^{8,9}$ While, the results of a clinical study which has been conducted on 30 overweight people showed that the consumption of instant coffee enriched with chlorogenic acid for 12 weeks showed a significant decrease in body mass index and body fat, compared with control. ${ }^{10}$

Kombucha is a traditional fermented tea with a slightly sour and sweet taste and is beneficial for health. This tea is widely consumed by people in all parts of the world. In the past, it was used in China, Russia, and Germany. Kombucha is ready to drink after its $\mathrm{pH}$ ranges from 2.5-3.5 with a fermentation time of $10-14$ days. ${ }^{11}$ Kombucha is defined as a combination of bacteria and yeast or commonly called 'SCOBY' ('symbiotic colony of bacteria and yeast'), where microorganisms create symbiotic relationships in the matrix in the form of fibers 
resembling mycelium. ${ }^{12}$ Acetobacter xylinum is the primary bacterium found in kombucha culture. The primary species of yeast successfully isolated from kombucha is Saccharomyces cerevisiae. ${ }^{13}$

Kombucha has been proven to increase stamina, intensify the work of the small intestine, lose weight, reduce cholesterol, normalize the functions of organs, treat gout, prevent cancer and increase immunity. ${ }^{14-16}$ Thus, there has been considerable interest in adding kombucha to coffee. The process of adding kombucha culture to robusta green coffee has been conducted by using a fermentation method where fermentation is defined as a process to generate useful products by utilizing microorganisms as a part of further processing. ${ }^{17}$

Assessing the toxicity of preparation or compound can be done using in vivo methods. In vivo acute toxicity tests can be carried out using zebrafish embryos (Danio rerio). ${ }^{18}$ Toxicity tests using species of fish are also an important element of whole effluent toxicity (wet) testing in North America and some European countries. ${ }^{19,20}$ Based on these conditions, this research was aimed to determine $\mathrm{LC}_{50}$ values for robusta green coffee fermented with kombucha culture by using an in vivo method involving zebrafish (Danio rerio) embryos.

\section{MATERIALS AND METHODS}

\section{Materials}

The materials and tools used were robusta green coffee beans from Garut, Indonesia, kombucha culture (Indokombucha), sucrose, water, E3 Medium $\left(5.0 \mathrm{mM} \mathrm{NaCl} ; 0.17 \mathrm{mM} \mathrm{KCl} ; 0.33 \mathrm{mMCaCl}_{2} ; 0.33 \mathrm{mM}\right.$ $\mathrm{MgSO}_{4}$ ) (Merck), dichloroaniline, filter membrane $0.45 \mu \mathrm{m}$, as well as Zebrafish (Danio rerio) wild-type Bogor.

\section{Research design}

This research was experimental design using in vivo methods (zebrafish embryos) to determine acute toxicity test in robusta green coffee fermented with the kombucha culture. In this study used 20 zebrafish embryos using five concentrations of kombucha coffee preparations, then the development of these embryos was observed every 24 hours up to 96 hours, and experiment was repeated 3x times. This research received registered ethical approval from Padjajaran University, No. 268/UN6.KEP/EC/2019.

\section{Fermentation of Kombucha Coffee}

Robusta green coffee beans were put into boiling water with a ratio of $375 \mathrm{mg}$ of simplicia per $300 \mathrm{~mL}$ of water, then $30 \mathrm{~g}$ of sucrose was added and stirred until homogeneous, then the mixture was cooled and strained. After that, $30 \mathrm{~mL}$ of kombucha vinegar was added and stirred until homogeneous. Then, $\pm 20 \mathrm{~g}$ of kombucha culture with $10^{8}$ $\mathrm{CFU} / \mathrm{ml}$ (symbiosis between the bacteria Acetobacter xylinum with several types of yeast that have been isolated from Kombucha such as Saccharomyces sp., Torulopsis famat, Pichia membranae, and Candida $\mathrm{sp.}^{21,22}$ was inoculated into each jar. The jar containing the inoculant was covered with a sterile porous cloth and placed in an incubator. The test was carried out at room temperature of $\pm 25^{\circ} \mathrm{C}$. The incubation time used was 18 days. The procedure was modified from standard kombucha fermentation with tea by previous study. ${ }^{11}$

\section{Phytochemical screening and simplicial characterization}

Phytochemical screening was carried out on the simplicia of robusta coffee beans as well as those that have been fermented using kombucha culture, including screening for alkaloids, flavonoids, saponins, steroids/ triterpenoids, tannins, and quinines. The screening procedures for each phytochemical was based on Indonesian Herbal Pharmacopoeia without any modification.

\section{Zebrafish maintenance}

Healthy adult zebrafish (Danio rerio) from wild type strain (3-4 months), were used in the experiment and kept in an aquarium at room temperature with the addition of bright lighting for 14 hours and 10 hours of dark cycles. The fish were fed using Tetramin twice a day in the morning and evening. Meanwhile, the aquarium water was replaced every 3 days by replacing $60 \%$ of the aquarium water volume to prevent drastic changes in the aquarium environment. ${ }^{23}$

\section{Toxicity test using zebrafish embryos}

Breeding was done by placing male and female zebrafish in a ratio of 2:1 into a breeding tank that has been installed with a net to separate the embryo from adult fish and left overnight. Zebrafish egg collection was carried out in the morning according to the lighting cycle using a fine net. Furthermore, the eggs obtained were washed with running water several times in order to remove any dirt that adhered to the egg. Then the embryos were observed under a stereomicroscope. Healthy or fertile embryos were then transferred to some Petri Dish embryos containing E3 medium. Embryos that died or were infertile appeared white or opaque and the separation was done after the first few hours of the development phase (0-96 hours post-fertilization (hpf)) by using a pipette to prevent a delay in the development of healthy embryos. ${ }^{23,24}$ Furthermore, the eggs were acclimatized in an incubator at $28-29^{\circ} \mathrm{C}$ for 2-3 hours before being given the test treatment.

The test solution of kombucha coffee was made by mixing kombucha coffee with E3 (reconstituted water) medium. E3 medium is a medium which was used as a zebrafish embryo maintenance medium. The composition of E3 medium (per 1 L) contained: $5.0 \mathrm{mM} \mathrm{NaCl} ; 0.17 \mathrm{mM}$ $\mathrm{KCl} ; 0.33 \mathrm{mM} \mathrm{CaCl}, 0.33 \mathrm{mM} \mathrm{MgSO}_{4}$. After that, five concentrations of test solutions of kombucha coffee were determined as follows: 100 ppm; 200 ppm; 300 ppm; 500 ppm; 1000 ppm, with a ratio of each concentration of 1.8. Positive controls used in the test treatment were in the form of $4 \mathrm{mg} / \mathrm{l}$ of Dichloroaniline, while the negative control was in the form of E3 solution. Zebrafish embryos at $6 \mathrm{hpf}$ were transferred into a 24 -well plate ( 1 embryo per well) and every 20 embryos were compared in each group. Then, to the wells were added the various concentrations of the Kombucha coffee extract solution, i.e., 100, 200,300,500 and 1000 ppm per well with 3 repetitions. A static nonsurrogate regime was used. Thus, there was no replacement for the test solution refresh during the test. Furthermore, the well plate containing the embryo and variations in the concentration of the kombucha coffee extract solution was incubated at $28{ }^{\circ} \mathrm{C}$. The replacement of the test solution was carried out every 24 hours to 96 hours of observation time. The toxicity test of kombucha coffee was repeated 3 times. ${ }^{25}$

The observations were carried out every 24 hours by observing and recording the number of dead embryos based on these characteristics: coagulated embryo, non-detachment of the tail, lack of somite formation, lack of heartbeat. If one of these characteristics appears in the embryo, the embryo was classified as a dead embryo. The activities of acute toxicity test of kombucha coffee using zebrafish embryos were based on OECD 236 of 2013 are: carrying out egg production, collecting eggs, conducting pre-exposure immediately after fertilizing in a glass container, selecting fertilized eggs with inverted microscope or binoculars and distributing fertilized eggs into containers with 24 wells prepared with each concentration/test control, $\mathrm{n}=$ number of eggs needed per concentration/control test (here is 20), as well as hours postfertilization monitored. ${ }^{25}$ The research scheme can be seen in Figure 1.

\section{Statistical analysis}

All data are expressed as mean \pm SD (Standard Deviation). Statistical analysis was performed using IBM SPSS Ver 23 software (IBM Corporation, North Castle, New York, USA). Statistical comparisons 


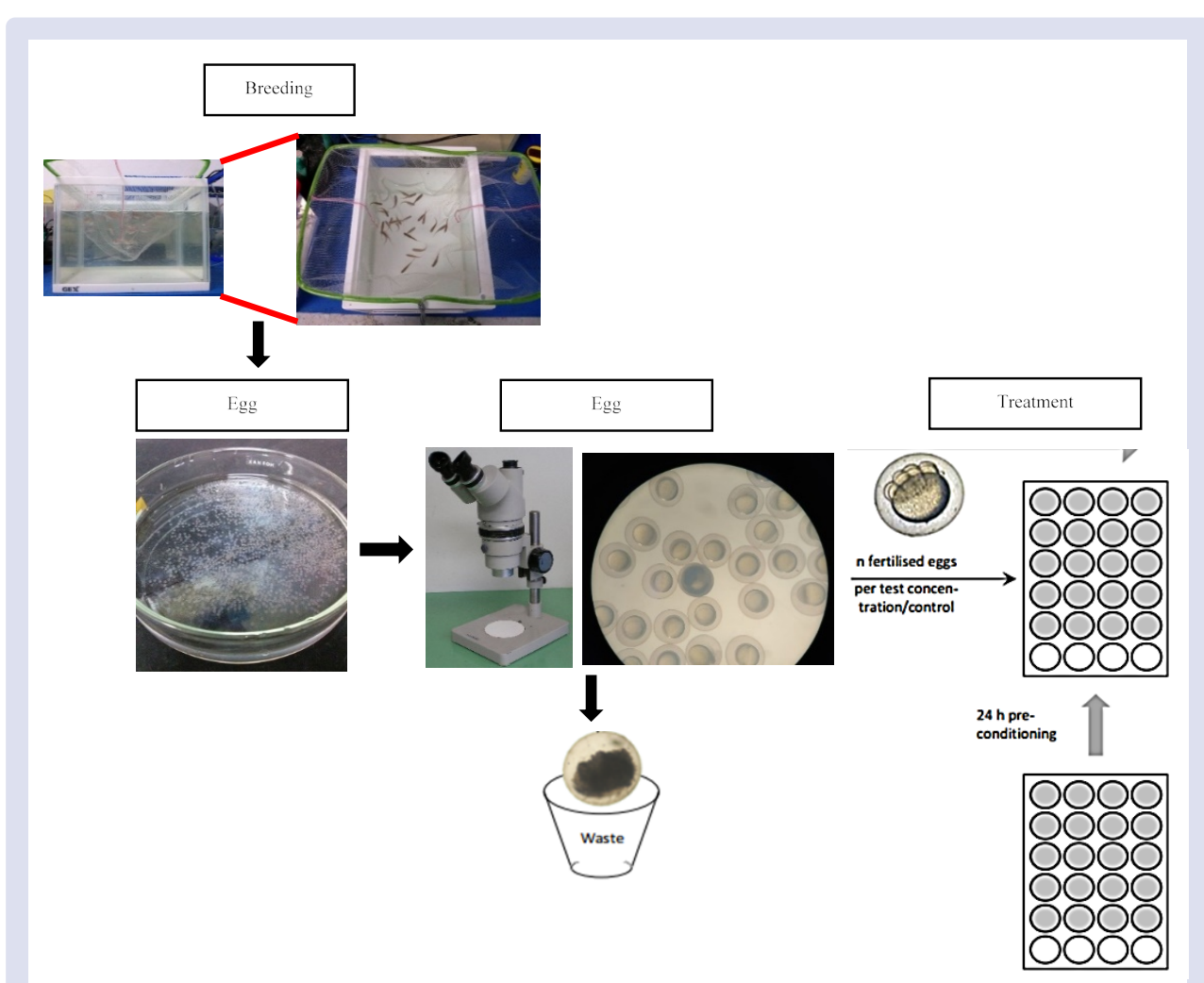

Figure 1: The procedural scheme of toxicity test using zebrafish embryos (OECD, 2013).

were assessed with one-way ANOVA followed by an LSD mutation comparison test with a significance level of 0.05 .

\section{RESULTS AND DISCUSSION}

Phytochemical screening was carried out to determine the chemical compounds contained in robusta green coffee beans. Phytochemical screening was carried out both on simplicia and kombucha coffee formed from the result of fermentation. The results of the phytochemical screening are listed in Table 1, and the results of simplicia characterization and standardization can be seen in Table 2.

Based on Table 1, it shows that simplicia and kombucha coffee contained alkaloids, flavonoids and tannin compounds. Steroids/Triterpenoids were found in the simplicial as the blue and green color indicator for steroids and the orange, yellow, and golden indicator for terpenoid were formed. ${ }^{26}$ There were no saponins and quinone either in simplicia and kombucha coffee as the formed bubbles were unstable for saponin test and no red indicator appeared after $\mathrm{NaOH}$ addition for quinone test. ${ }^{27}$

The alkaloid substance in green coffee is caffeine. Caffeine is a nonspecific antagonistic for adenosin receptor, which is widely distributed in the cortex. ${ }^{28}$ The caffeine is a stimulant that works by inihibiting adenosin receptor, thus blocking the neurotransmitter. ${ }^{29}$ The simplicia and the green coffee kombucha extract also had cholorogenic acid flavonoid, a strong antioxidant in the group of hydroxycinnamic acid group that commonly found in coffee and tea. ${ }^{6}$ Roasting can reduce the chlorogenic acid; the darker the beans, the least amount of chlorogenic acid will be ${ }^{30}$ Roasting temperature also affect the content; the higher temperature will further decrease the antioxidant activity. ${ }^{31}$

Interestingly, the phytochemical screening of the green robusta coffee bean simplicia and coffee kombucha showed a different result with previous study ${ }^{32}$, who reported alkaloid, tannin, saponin, flavonoid, terpenoid content in the robusta coffee beans. These results indicated the secondary metabolite content in coffee beans was affected by type, processing, and geographical origin. ${ }^{33}$
Table 1: The results of the phytochemical screening of simplicia and kombucha coffee.

\begin{tabular}{ccc}
\hline & \multicolumn{2}{c}{ Coffee Bean } \\
\hline Groups & Simplicia & Kombucha Coffee \\
\hline Alkaloids & + & + \\
Flavonoids & + & + \\
Saponins & - & - \\
Steroids/Triterpenoids & + & + \\
Tannins & + & + \\
Quinone & - & - \\
\hline
\end{tabular}

(+) : identified; (-) : not identified.

Table 2: The results of simplicia characterization.

\begin{tabular}{cc}
\hline Parameter & Result (\%w/w) \\
\hline Water-soluble extract content & $18.56 \pm 0.21$ \\
Ethanol soluble extract content & $13.42 \pm 0.13$ \\
Water content ${ }^{*}$ & 9.14 \\
Total ash content & $2.83 \pm 0.08$ \\
Acid insoluble ash content & $1.04 \pm 0.02$ \\
\hline
\end{tabular}

$(*) \% \mathrm{v} / \mathrm{w}$

As seen in Table 2, the simplicia characterizations carried out include the determination of water-soluble extract content, ethanol-soluble extract content, water content, total ash content, and acid insoluble ash content. The water content of robusta coffee used in this study was 9.14\%. Moisture content can guarantee safety during the storage process. This water content corresponds to the robusta coffee water range in general, which is $7-13 \%{ }^{34}$ In this research, water is used as a solvent because water has a better ability to dissolve bioactive compounds in Robusta coffee than isopropanol. Also, water is able to dissolve other components such as carbohydrates, aroma-forming compounds, and colors. ${ }^{4}$ The acute toxicity test of kombucha coffee using zebrafish 
resulted in the regression equation in percent (\%) of the concentration of kombucha coffee seen in Table 3 and Figure 2.

Based on Table 3, shows that the higher the concentration (ppm) of kombucha coffee given to zebrafish the higher the mortality percentage, which is $32 \%$ at $1000 \mathrm{ppm}$, so that the probit value is 4.53 .

Based on Figure 2, the regression equation of the results of an acute toxicity test using zebrafish with the observation time of 96 hours is obtained, and the $\mathrm{LC}_{50}$ value for kombucha coffee is $1294.29 \mathrm{ppm}$. These results are obtained from the equation $\mathrm{y}=0.0014 \mathrm{X}+3.188$. Solving for a probit value for $\mathrm{LC}_{50}=5$, an $\mathrm{x}$ value of $1294.29 \mathrm{ppm}$ can be obtained. This is based on whether there are features: coagulated embryo, Nondetachment of the tail, lack of somite formation, lack of heartbeat. $\mathrm{LC}_{50}$ or Lethal Concentration 50 is the concentration that causes death as much as $50 \%$ of the test organisms. The OECD categorized the toxicity of pollutants in a zebrafish model as being dangerous (10 ppm $\left.<\mathrm{LC}_{50}<100 \mathrm{ppm}\right)$, toxic $\left(1 \mathrm{ppm}<\mathrm{LC}_{50}<10 \mathrm{ppm}\right)$, and very toxic $\left(\mathrm{LC}_{50}<1\right.$ $\mathrm{ppm})$. Based on these categories, kombucha coffee is included in the safe category. The characteristics seen in the zebrafish embryo during 96 hpf observation can be seen in Figure 3.

Based on Figure 3, it can be seen that there are defects in the zebrafish embryo which was given kombucha coffee during 96 hpf observation, indicated by lack of somit formation, pericardial edema and spinal curvature (scoliosis). Therefore, based on this observation, the embryo is classified as a dead embryo.

Zebrafish embryos exposed to dichloroaniline resulted in death at the 24th hour before the hatching process took place. According to Kumar et al., this condition is thought to occur due to interference with cell organelles, as well as mitochondria as a place for aerobic respiration. ${ }^{35}$ The process of ATP formation is slow or stopped, resulting in the failure of the active membrane of the sodium pump, intracellular sodium accumulation, and outward diffusion of potassium, which can kill cells. Cells that experience continual swelling can result in lysis of the cell wall, and this can impact all of the cell organelles (necrosis).

Somit formation abnormalities in zebrafish embryos can be caused by the inhibition of Fibroblast Growth Factor (FGF) by genistein, which is expressed more in the posterior region. ${ }^{36}$ so that it can make easier for Retinoic Acid (RA) to increase the expression of genes determining the somite pattern, while FGF suppresses RA activity and inhibits presomitic mesoderm maturation into somites. RA is expressed in a rostrocaudal gradient, while FGF is expressed in a caudorostral gradient. $^{37}$

Pericardial edema abnormalities in zebrafish embryos according to Kim et. al can occur due to exposure to genistein which can reduce the frequency of zebrafish heart rates. ${ }^{38}$ Genistein is a tyrosine kinase inhibitor that functions to influence the activity of various ion channels, both through the process of phosphorylation and direct bonding. Meanwhile, according to Chen which explains that pericardial edema can occur because it is influenced by many factors. Factors that cause zebrafish embryos to experience stress due to treatment using any means will have an impact on the occurrence of impaired heart function (pericardial edema) and impaired circulation. ${ }^{39}$

Body axis abnormalities that occur in zebrafish embryos due to kombucha coffee namely bent and curly up. Bent body axis abnormalities

Table 3: The results of the calculation of mortality percentage and probit value.

\begin{tabular}{cccccc}
\hline $\begin{array}{c}\text { Concentration } \\
(\mathrm{ppm})\end{array}$ & $\mathbf{1}^{*}$ & $\begin{array}{c}\text { \%ortality } \\
\mathbf{2}^{*}\end{array}$ & $3^{*}$ & Percentage (\%) & Palue \\
\hline 100 & 5 & 5 & 5 & 5 & 3.36 \\
200 & 10 & 5 & 0 & 5 & 3.36 \\
300 & 15 & 5 & 0 & 7 & 3.52 \\
500 & 25 & 5 & 30 & 20 & 4.16 \\
1000 & 25 & 10 & 60 & 32 & 4.53 \\
\hline
\end{tabular}

$\left(^{*}\right)$ repetition using the same methods

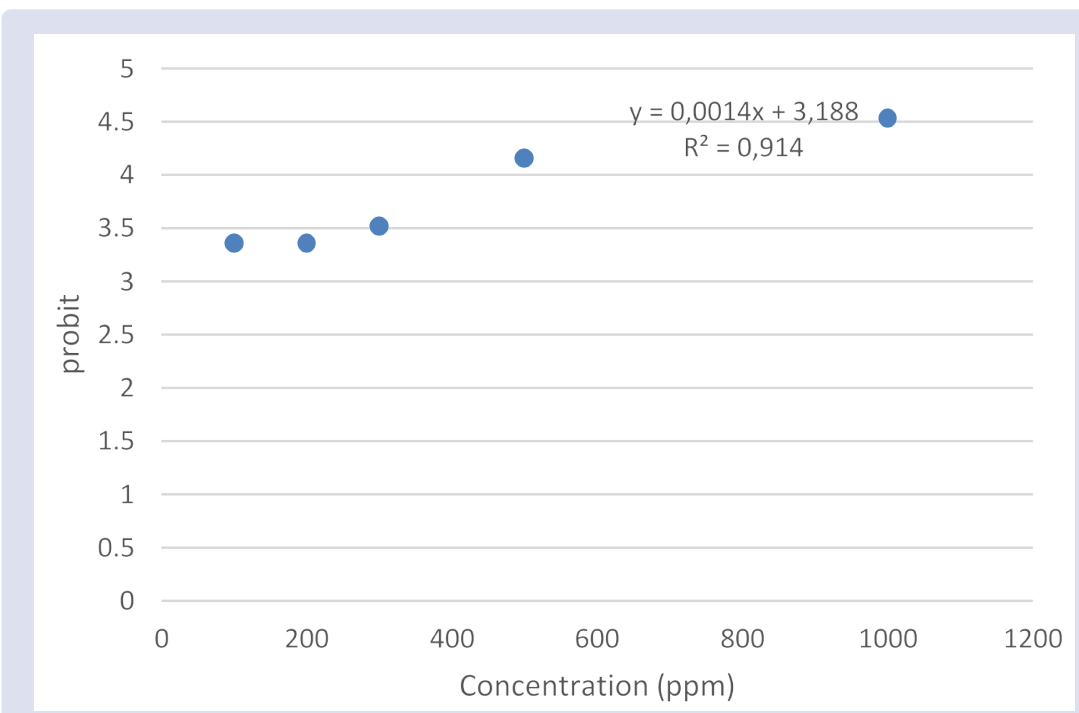

Figure 2: The curve between Probit vs Concentration (ppm) of kombucha coffee in the acute toxicity test towards zebrafish embryos. The regression equation obtained is $y=$ $0.0014 X+3,188 ; R^{2}=0.914$ 


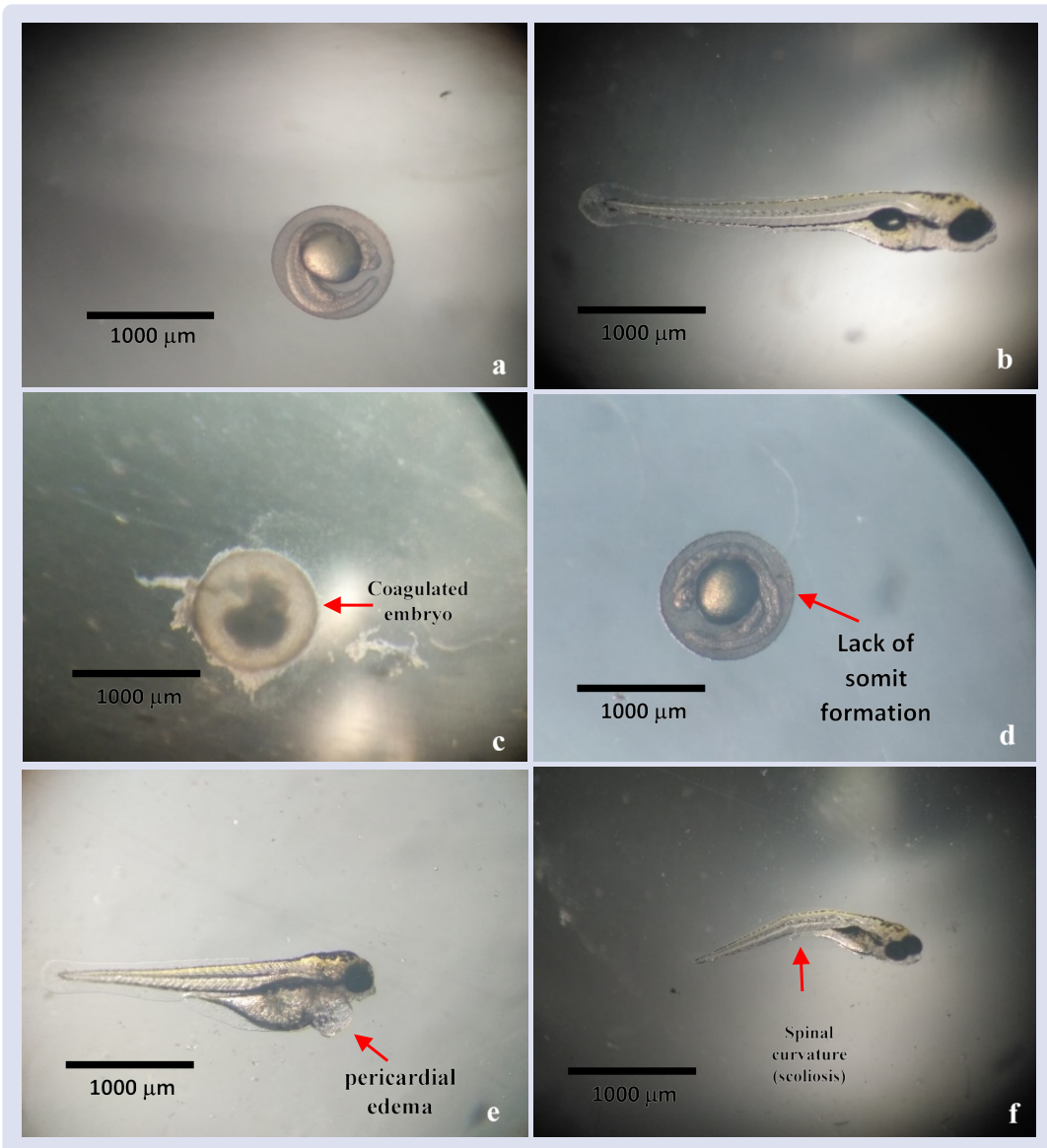

Figure 3: Examples of zebrafish conditions. Healthy: (a) negative control $24 \mathrm{hpf}$, (b) negative control $96 \mathrm{hpf}$ (c) Positive control (Dichloroaniline $4 \mathrm{mg} / \mathrm{l}$ ), Characters appeared in the zebrafish embryo after $96 \mathrm{hpf}$ (observation zebrafish embryo classification deemed dead according to the OECD, 2013), (d) 500 ppm 24 hpf (lack of somit formation), (e) 1000 ppm 96 hpf (pericardial edema), (f) 300 ppm 96 ppm (scoliosis).

(Figure 3f) are shown to the body bent sideways due to damage to the spinal cord, while curly up body axis abnormalities are shown with the body bent up which occurs due to the influence of the Polaris gene and pkd2 (polycystin) and $\beta$-catenin protein. ${ }^{40,41}$

Acute toxicity test using zebrafish embryos is intended to obtain safe preparation, where the measured parameter is $\mathrm{LC}_{50}$. The data in Table 3 show a safety level of $95 \%$ at concentrations of 100 and $200 \mathrm{ppm}, 93 \%$ for concentrations of $300 \mathrm{ppm}$ and decreased to $80 \%$ at concentrations of $500 \mathrm{ppm}$ and $1000 \mathrm{ppm}$ to $68 \%$. From the results of the toxicity test on kombucha coffee, the $\mathrm{LC}_{50}$ value of $1294.29 \mathrm{ppm}$ is obtained. This value, if it is classified using the category of OECD, is included in the safe category. Therefore, based on these conditions, green kombucha coffee is safe for consumption. It is important to develop green coffee kombucha with green coffee ingredients so that a clear toxicity description can be obtained about the types of coffee used as the basic ingredients of fermented coffee drinks.

\section{CONCLUSION}

Based on $\mathrm{LC}_{50}$ values, $1294.29 \mathrm{ppm}$, obtained from the test using zebrafish embryos and classified according to the OECD category, kombucha coffee is included in the safe category. This condition is also thought to occur in kombucha coffee with arabica green coffee ingredients.

\section{ACKNOWLEDGMENTS}

We would like to express our gratitude to the School of Life Sciences and Technology and school of pharmacy of ITB for providing us the laboratory facilities during the implementation of the research so that it can be carried out well.

\section{REFERENCES}

1. International Coffee Organization (ICO) [homepage on the Internet]. Glossary of Term Used; [updated 2012; cited 2019 Dec 18]. Available from: http://www ico.org/glossary.asp

2. Kummer C. Caffeine and decaf: The joy of coffee. New York: Houghton Mifflin 2003.

3. Amanda P. [homepage on the Internet]. The 4 main types of coffee beans: $A$ complete guide; [updated 2019; cited 2019 Dec 18]. Available from: https:// coffee-channel.com/different-types-coffee-beans/

4. Naidu MM, Sulochanamma G, Sampathu SR, Srinivas P. Studies on extraction and antioxidant potential of green coffee. Food Chem. 2008;107(1):337-84.

5. Narita Y, Inouye K. Chlorogenic acids from coffee. In: Preedy VR, Editor. Coffee in Health and Disease Prevention. US: Elsevier.

6. Scheiber A, And MDA. Saldana. Potato peels: A source of nutritionally and pharmacologically interesting compounds - a review. Global Sci. 2009;3(SI2):23-8.

7. Johnston KL, Clifford MN, Morgan LM. Coffee acutely modifies gastrointestinal hormon secretion and glucose tolerance in human: Glycemic effect of chlorogenic acid and caffeine. Am J Clin Nutr. 2003;78(4):728-33.

8. Shimoda H, Seki E, Aitani M. Inhibitory effect of green coffee bean extract on fat accumulation and body weight gain in mice. BMC Complement Altern Med. 2006;6:9-15. 
9. Onakpoya I, Terry R, Ernst E. The use of green coffee extract as a weight loss supplement: a systematic review and meta-analysis of randomised clinical trials. Gastroenterol Res Pract. 2011:382852.

10. Cornelis MC. Toward systems epidemiology of coffee and health. Curr Opin Lipidol. 2015;26:20-9.

11. Jayabalan R, Malba`sa RV, Lon`car ES, Vitas JS, Sathishkumar M. A review on kombucha tea-microbiology, composition, fermentation, beneficial effects, toxicity, and tea fungus. Compr Rev Food Sci Food Saf. 2014;13(4):538-50.

12. Karamadin MK, Bazzaz BS, Rezael A, Montazeri K. Antimicrobial activity of tea fungus kombucha. Proceeding of the 138th British Pharmaceutical Conference: 2001. Glasgow.

13. Blanc PJ. Characterization of the tea fungus metabolities. London: Pearson Education; 2000

14. Alick, Barthomelow M. [homepage on the Internet]. Kombucha tea therapy. [updated 2002; cited 2019 Dec 18]. Available from: http://www.positivehealth. com/permit/article/nutrition/kombucha.htm.

15. Adriani L, Mayasari N, Kartasudjana AR. The effect of feeding fermented kombucha tea on hdl, Idl and total cholesterol levels in the duck bloods. Biotechnol. Anim Husb. 2011;27(4):1749-55.

16. Leal JM, Suarez LV, Jayabalan R, Oros JH, Escalante-Aburto A. A review on health benefits ofkombucha nutritional compounds and metabolites. Cyta-J Food. 2018;16(1):390-9

17. Seyedin A, Hatamian-zarmi A, Rasekh B. Natural pigment production by Monascus purpureus: Bioreactor yield improvement through statistical analysis. Applied Food Biotechnology. 2015;2(2):23-30.

18. MacRae CA, Peterson MR. Zebrafish as tools for drug discovery. Nat Rev Drug Discov. 2015;14(10):721-31

19. Braunbeck T, BöttcherM, Hollert H, KosmehI T, Lammer E, Leist E, et al. Towards an alternative for the acute fish LC50 test in chemical assessment: The 8 fish embryo toxicity test goes multi-species - an update. Altex 2005;22:87-102

20. Nagel R. Dar T. The embryo test with the zebrafish (Danio rerio) - a general model in 13 ecotoxicology and toxicology. Altex. 2002;19:38-48.

21. Greenwalt CJ, Steinkraus KH and Ledford RA. Journal of Food Protection. 2000; 63(7):976-981.

22. Teoh AL, Heard G, Cox J. Yeast Ecology of Kombucha Fermentation. Int J Food Microbiol. 2004; 95(2):119-26.

23. Avdesh A, Chen M, Martin-Iverson MT, Mondal A, Ong D, Rainey-Smith S, et al. Regular care and maintanance of a zebrafish (Danio rerio) laboratory: An introduction. J Vis Exp. 2012:18(69):e4196.

24. Harper C. Lawrence C. The laboratory zebrafish. Boca Raton: CRC Press; 2011.
25. OECD. Test No. 236: Fish Embryo Acute Toxicity (FET) test, OECD guidelines for the testing of chemicals, section 2, Paris: OECD Publishing; 2013.

26. Tiwari, Prashant, Kumar B, Kaur M, Kaur G, Kaur H. Phytochemical Screening and Extraction: A Review. International Pharmaceutica Sciencia. 2011;1(1):98-106.

27. Hanani E. 2015. Analisis Fitokimia. ECG. Jakarta.

28. Ryan, Lee, Hatfield, Colleen, Hofstetter, Melissa. Caffeine Reduces TimeofDay Effect on Memory Performance in Older Adult. Psychological Science: A Journal of the American Psychological Society. 2002;13(1):8-71.

29. Ramachandran VS. Encyclopedia of The Human Brain Vol. 4. New York: Academic Press, Inc. 2002.

30. Belay A, Gholap AV. Characterization and determination of chlorogenic acids in coffee beans by UV-spectroscopy. African Journal of Pure and Applied Chemistry. 2009;3(11):234-40.

31. Cammerer B, Lothar W Kroh. Antioxidant activity of coffee brews. Eur Food Res Technol. 2006;223:469-74.

32. Chairgulprasert V, Kittiya K. Preminary phytochemichal screening and antioxidant of robusta coffee blossom. Thammasat International Journal of Science and Technology. Thailand. 2017;22(1):1-8.

33. Tamilmani P, Pandey MC. Optimization and elaviation of phenolic coumpound and their antioxidant activity from coffee beans. International Journal of Advanced Research. 2015;3(4):296306.

34. Belitz HD, Grosch W, Schieberle P. Food chemistry. Berlin: Springer Verlage Berlin Heidelberg; 2009.

35. Kumar V, Cotran RS, Robbins SL. Basic pathology. 7th ed. Philadelphia: WB Saunders; 2002.

36. Colas JF, Schoenwolf GC. Towards a cellular and molecular understanding of neurulation. Dev Dyn. 2001;221(2):117-45.

37. Saddler TW. Langman's medical embryology.10th ed. Philadelphia: Lippincott Williams \& Wilkins; 2006

38. Kim DJ, Seok SH, Baek MW, Lee HY, Na YR, Park SH, et al. Developmental toxicity and brain aromatase induction by high genistein concentrations in zebrafish embryos. Toxicol Mech Methods. 2009;19(3):251-6.

39. Chen J. Impaired cardiovascular function caused by different stressors elicits a common pathological and transcriptional responses in zebrafish embryos. Zebrafish. 2013:10(3):389-400.

40. Bisgrove BW, Snarr BS, Emrazian A, Yost HJ. Polaris and Polycystin-2 in dorsa forerunner cells and Kupffer's vesicle are required for specification of the zebrafish left-right axis. Dev Biol. 2005;287:274-88.

41. Schier AF, Talbot WS. Molecular genetics of axis formation in zebrafish. Annu Rev Genet. 2005;39:561-613. 


\section{GRAPHICAL ABSTRACT}

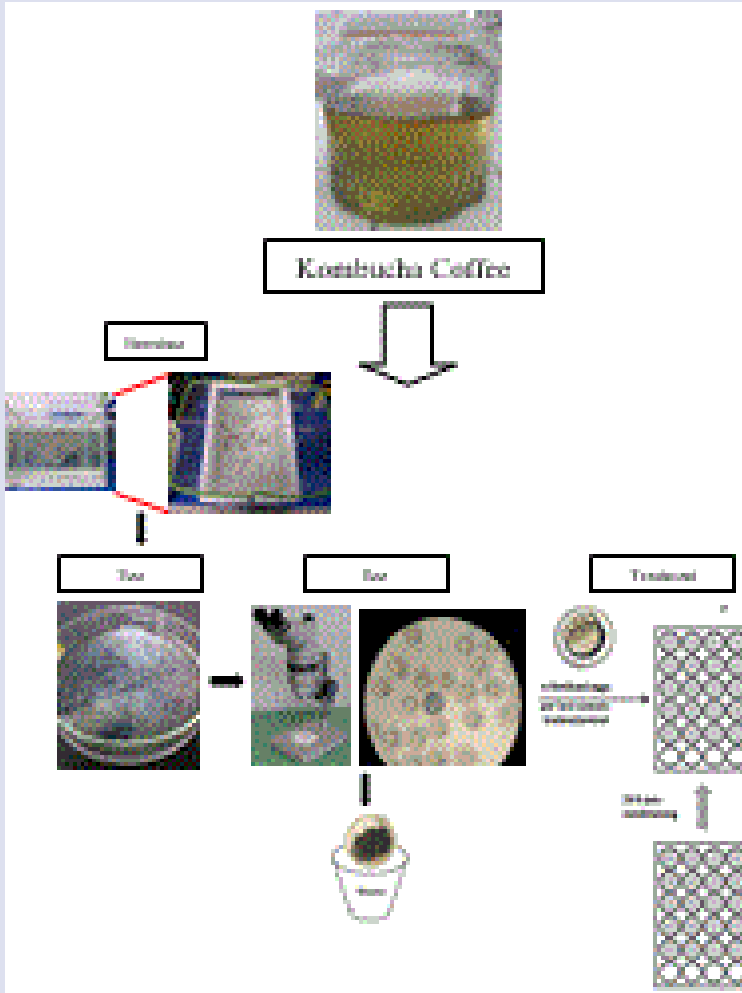

The precedunal scterte of waxicily keit wsing zetseafish entarwus LOECD. 20131
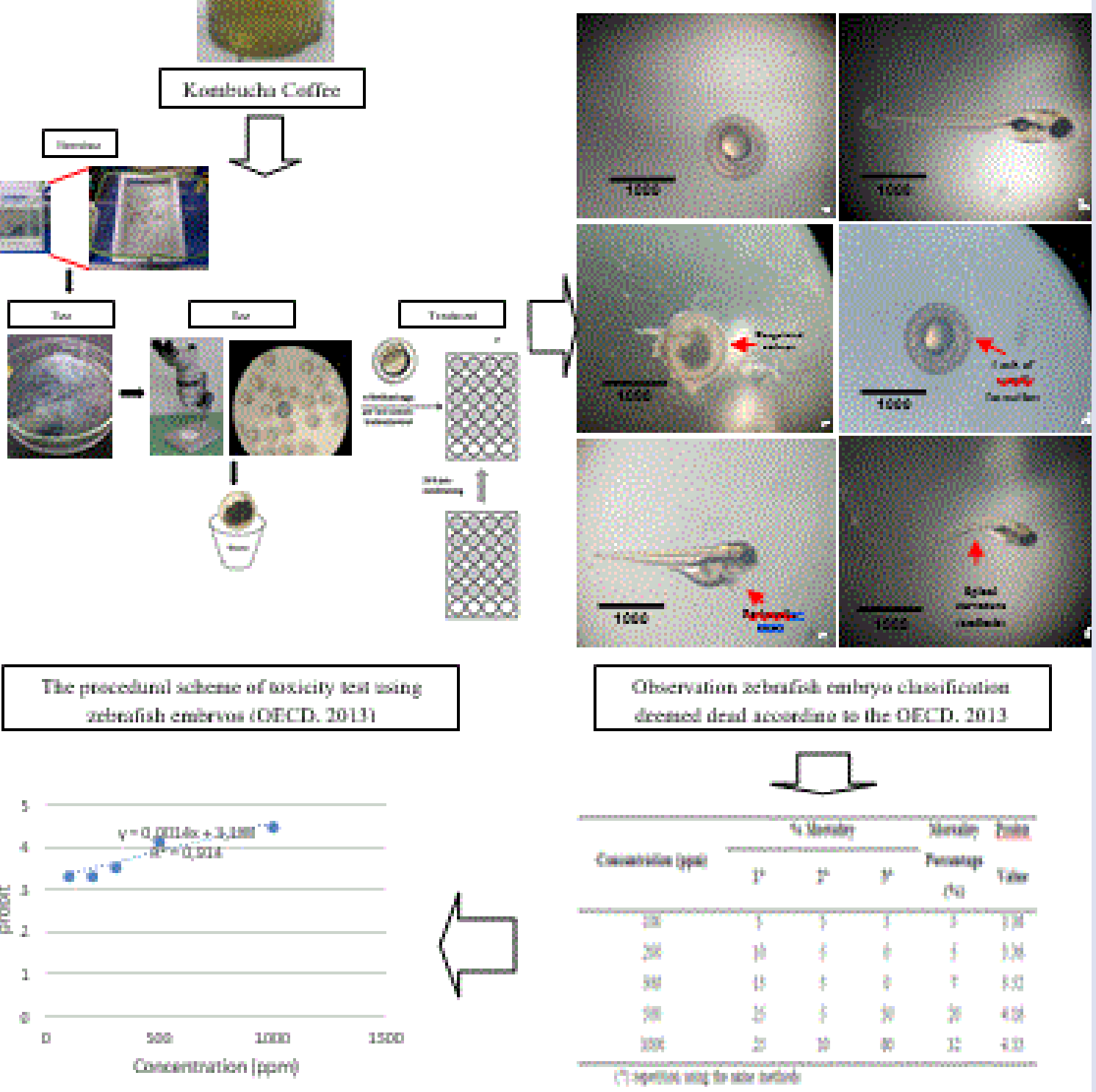

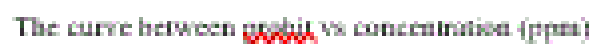
of leminule colfes

The results of the calculation of anitasty fercerkate ated reobid value.

Otriervation sebrafich entryo chesificutisa

drested deal acosolines wo the OECD. 2013

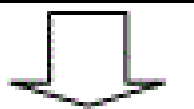

$\mathrm{LC}_{n}$ 


\section{ABOUT AUTHORS}

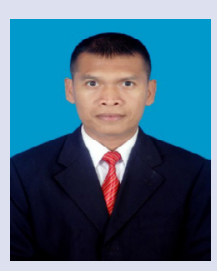

\section{Tedjo Narko}

Poltekkes TNI AU, Jalan Ciumbuleuit No. 203 Bandung, Indonesia. Tedjo Narko is currently a doctoral student at the School of Pharmacy, Bandung Institute of Technology.

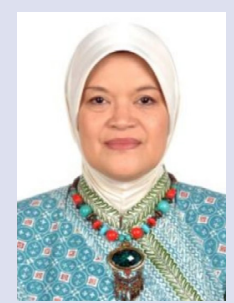

\section{Prof. Marlia Singgih Wibowo, Ph.D., Apt.}

Department of Pharmacochemistry, School of Pharmacy, Bandung Institute of Technology, Jalan Ganesha 10 Bandung, Indonesia.

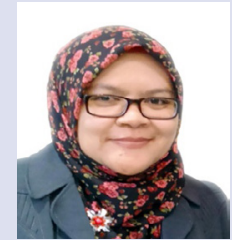

\section{Dr. rer. nat. Sophi Damayanti, M.Si., Apt.}

Department of Pharmacochemistry, School of Pharmacy, Bandung Institute of Technology, Jalan Ganesha 10 Bandung, Indonesia.

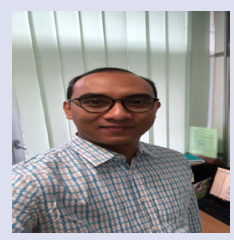

\section{Dr. Indra Wibowo, S.Si., M.Sc.}

Department of Biology, School of Life Sciences and Technology, Bandung Institute of Technology, Jalan Ganesha 10 Bandung, Indonesia.

Cite this article: Narko T, Wibowo MS, Damayanti S, Wibowo I. Acute Toxicity Tests of Fermented Robusta Green Coffee Using Zebrafish Embryos (Danio rerio). Pharmacogn J. 2020;12(3):485-92. 